\title{
A Study of Crisis Scheduling Method Based on APTS Ya-Yun ZHU ${ }^{1, a}$, Jian-Xiao MA ${ }^{1, b,{ }^{*}}$, Chun-Hua TAN ${ }^{2, c}$, De-Kai ZHOU ${ }^{1, d}$ \\ ${ }^{1}$ Nanjing Forestry University, Nanjing Jiangsu 210037, China \\ ${ }^{2}$ Baotou Landscape Company, Baotou Neimenggu 014000, China \\ azhuzhulqm@163.com, bjxma@163.com, cybgy3323778@163.com, 'zhoudekai@vip.qq.com \\ ${ }^{*}$ Corresponding author
}

Keywords: Intelligent Transportation System, Public Transit, Dynamic Scheduling, Crisis Scheduling.

\begin{abstract}
With the complexity increases of the Advanced Public Transportation Systems (APTS), the risk of traffic crisis rises. Through analyzing the characteristic of public traffic safety based on APTS, this paper combines " $3 \mathrm{G}$ " and ZigBee technologies to locate vehicles in time and get the information of exterior and interior situation of the vehicles. By means of these technologies, the crisis degree can be realized from two angles which are crisis identification and scheduling. The paper takes line dynamic scheduling as the principal thing, takes regional dynamic scheduling as supplement, and analyzes it in order to find new scheduling method when crisis happen.
\end{abstract}

\section{Introduction}

The emergence and the development of Advanced Public Transportation Systems (APTS) supply scientific management methods to alleviate urban traffic congestion. However, in the process of applying this technology, many problems will be emerging inevitably. Then, the safety, comfortable and convenient public transportation services may lose its competitive edge. Public transportation aims at serving the public, so its security is one of the most important components [1]. Because of the complicated urban problems, uncertainty and burstiness of public transport accidents, the safety problems of public traffic become complex extremely. In the public transportation systems, accurate positioning, inside situation of the vehicles, road conditions, vehicle scheduling.eg are the main aspects affect the efficiency and level public transport crisis management. The main theme of the paper is coordinating each aspect in order to reduce losses brought by the public crisis.

\section{Public Transportation Security Features}

Public transportation has its unique characteristics, including the density of crowd, the vulnerability of system and the sensitivity of consequences [2]. The crowd density brings about traffic accidents accompanied by serious consequences; it is easier to destroy the public traffic safety system because of the vulnerability of system; the sensitivity of consequences leads to enormous social impact that public transportation is prone to mutation.

The Density of Crowd. The density of urban population is becoming denser with the rapid economic growth. This makes urban public transportation overload, especially the bus and subway. In the event of traffic accident, public transportation often makes mass death and casualty.

The Vulnerability of System. The vulnerability of system means that in the public transportation security system, the anti-disaster ability of some links is weak. It may cause serious consequence once that traffic accident happened. In many cities, due to the imperfect road planning and the contradiction between traffic supply and demand caused by backward traffic infrastructure, the road is always in super saturation state during the peak. So it is easy to cause traffic accident.

The Sensitivity of Consequences. The serious consequences caused by public traffic accident have huge social sensitivity, because public traffic accidents have burstiness, once traffic happened, 
it is difficult to evacuate and rescue the crowd. Improper traffic disposal gives rise to massive loss of life and property, besides it brings negative effects to social economy and public life.

\section{Public Transportation Crisis Identification}

Urban public transportation crisis means the incident affected by social and nature uncertain factors that make public vehicles could not run on schedule table normally. But public traffic, passengers without safety inspection, has sociality. The public vehicles are always overloaded, so that it needs dispatching center to discom crisis accurately and take action on that.

\section{Vehicle Localization}

The accurate location of vehicle is extremely important when traffic crisis happened. Once the dispatching center computer system get the information of public vehicles timely, traffic controllers can master the distribution of public vehicles on lines and the conditions of passenger flow. Then traffic controllers manage vehicles reasonably with this information. When a section of bus route jams, dispatching center provides date and graph of vehicles. The efficiency of traffic crisis management improves.

APTS applies GPS, GIS, mobile communication technology and so on [3-5]. The positioning system based on "3G"technology can provide continuous, real-time and high-precision position and speed in 3D space for users. But the GPS signals are vulnerable to tall buildings, flyover and vegetation, especially tunnel.

ZigBee is a kind of communication technology with simple construction, low-power dissipation, low date rate, low-cost and two-way micro power grid of wireless network [6-8].New technology scheme takes advantage of this characteristic. I $t$ uses the same simple network combine the radio signal benchmarking positioning technology. Then the wireless transmission between vehicle positioning and other information can be realized. This paper fuse the two technologies and uses low cost ZigBee in a built-up area or mountain tunnels to make up the lack of „3G $3 \mathrm{G}^{\text {ecee }}$ technology, besides, it ensures accurate positioning of crisis public vehicles in any place and any time. The comparison of the two ways in table 1 :

Tab. 1 The Table of Merit and Demerit between "er $G^{\text {eee }}$ and ZigBee Technologies

\begin{tabular}{|c|c|c|c|}
\hline & advantage & disadvantage & applicability \\
\hline $\begin{array}{l}\text { "3G" } \\
\text { technology }\end{array}$ & $\begin{array}{c}\text { Remote } \\
\text { connection; } \\
\text { Precision } \\
\text { positioning; } \\
\text { Friendly } \\
\text { man-machine } \\
\text { interface }\end{array}$ & $\begin{array}{l}\text { High-cost and high-power; } \\
\text { Susceptible to disturbance }\end{array}$ & $\begin{array}{l}\text { Suitable for accurate } \\
\text { positioning vehicles with } \\
\text { no signal interference }\end{array}$ \\
\hline $\begin{array}{c}\text { ZigBee } \\
\text { technology }\end{array}$ & $\begin{array}{l}\text { Low-power; } \\
\text { Low-cost }\end{array}$ & $\begin{array}{l}\text { Short distance transmission; } \\
\text { Need to install node; } \\
\text { Weak sensitivity }\end{array}$ & $\begin{array}{l}\text { Positioning crisis vehicle } \\
\text { in the dense buildings area } \\
\text { or in the tunnels }\end{array}$ \\
\hline
\end{tabular}

"3G" navigational car terminal module as the mobile node in ZigBee wireless network needs to be installed on the buses. Fixed nodes are mainly distributed in transit site near building populated area and some other places where GPS signal is weak. When the distance between the two bus station is too far, adding a certain amount of relay wireless communication nodes between the bus stop. The number of fixed nodes determines the accuracy of public vehicles positioning. Generally according to the need, installing nodes in every $500 \mathrm{~m}-600 \mathrm{~m}$. When the bus lines bend, nodes need to be installed at the corner. 


\section{Situation in Vehicles}

Buses have car terminal which is a device that can acquire data, display information, control other equipments inside the car and communicate with the dispatch center and the ground control equipment [9-13]. Many cities started to develop intelligent bus, also the introduced advanced technology in vehicle terminal equipment, installed GPS positioning, voice stops, other vehicle terminal equipment such as liquid crystal display (LCD) etc.

" 3 G" technology has been widely used in transit operation. It can help bus to realize localization. The dispatching center grasps the information of vehicle location, and then center can extract some other information, including the driver information, passenger information, license plate number, speed, etc.

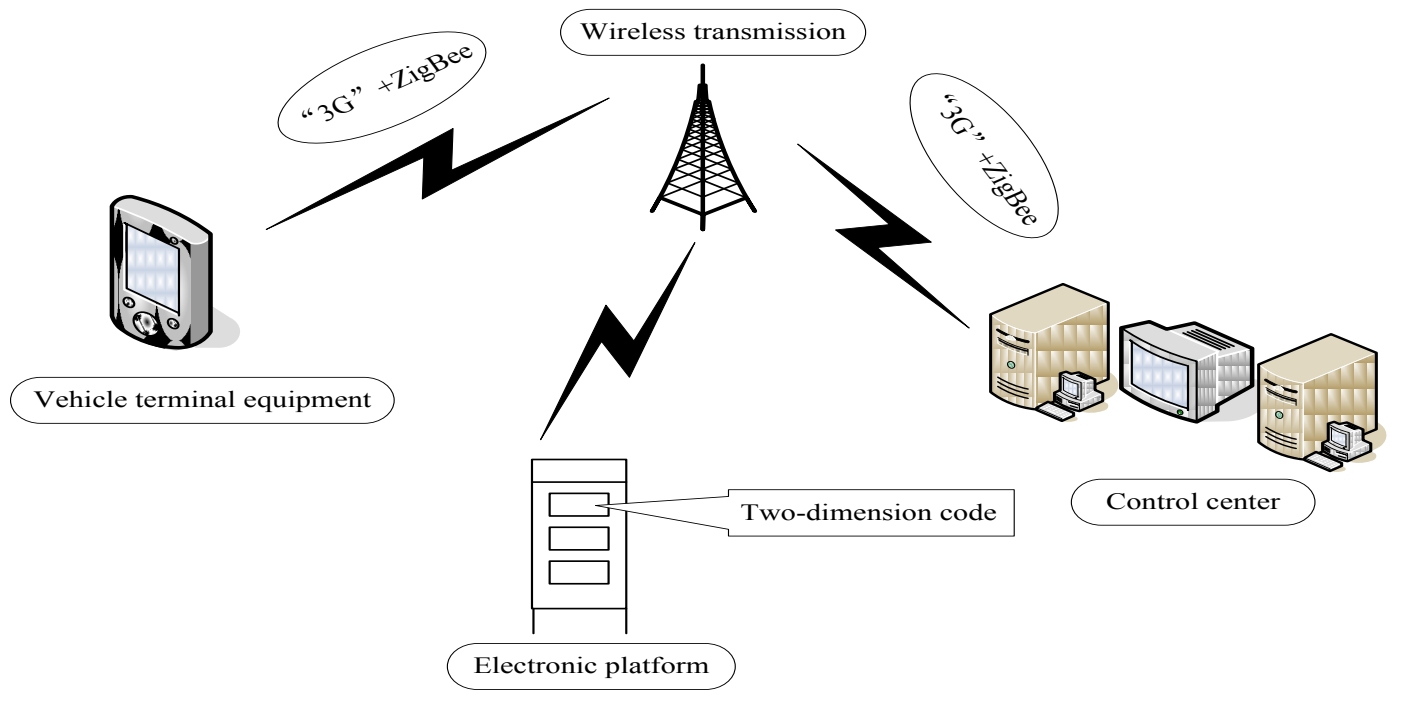

Fig. 1 Public Transportation Crisis Identification

Dispatching center observes passengers and situation in the vehicles through vehicle terminal equipment, at the same time the terminal equipment transmit localization information to control center. The driver is the main controller of the bus. When abnormal things happened on the bus, the driver gives crisis feedback to control center via text message or telephone. Dispatching center sends crisis management plan to information display screen, so that drivers can known how to manage imminently. It is a two-way interact communication. Specific crisis discriminating system shows in figure 1.

\section{Situation outside Vehicles}

The traffic information outside the bus is mainly analyzed by three ways . First, control center can demand the degree of road congestion timely through GIS and conduct a preliminary evaluation of public transportation crisis. Second, the vehicle terminal equipment connect information display screen and wireless telephone, dispatch center contact with the driver directly to know traffic situation. In addition, the cameras on key road section can also provide traffic condition for us to know the influence of transport crisis.

After analyzing the traffic situation, control center confirms reasonable scheduling scheme and changes information on electronic platform to tell passengers vehicle scheduling condition. In order to placate passengers ${ }^{\text {ee }}$ mood, passengers can also know bus running status through tow-dimension code.

\section{The Application Research of Bus Crisis Scheduling}

Public vehicle dispatching is the main aspect affecting the efficiency and level of the bus crisis management and is the core of advanced public transportation system [14]. 
The bus operation management mode can be divided into single line scheduling mode and regional scheduling mode.

\section{Single Line Scheduling}

Single line scheduling refers to line scheduling for one unit. When operating vehicles run into traffic delay, center control adjusts the original schedules properly with given system parameters and the information of road situation. Single line scheduling has less effect on the whole APTS. It is simpler to regional scheduling. So it is important to seek single line scheduling method to deal with traffic crisis. This paper divided single line scheduling into two ways.

In Rush Hours. In rush hours, passenger demand is high. Once a bus accident happened, the passengers in the car need to evacuate. The next bus on the same line arrives at crisis position quickly without stopping other platform. The departure point center adjusts the frequency and short appropriately part of vehicle departure interval to make up for peak shifts.

Flat Peak. Dispatching center usually adopt frequency modulation method. According to the actual traffic demand, it increases the departure interval without increasing the number of vehicles.

\section{Regional Scheduling}

Regional scheduling refers to the public traffic expand the size of the entities operating organization and scheduling changes a single line for multiple lines at an organic whole.

APTS provides technical support and guarantee for regional scheduling. Regional scheduling can be adopted when the single line scheduling mode can ${ }^{\text {i } t}$ meet requirement. It needs adjust major vehicles. It spends a large amount of time to arrange vehicles covered. So control center should minimize the adjustment range when public traffic crisis happened.

\section{Example}

Nanjing Xuanwu tunnel spans 2660 meters, the dark buried section is 2230 meters. One bus line is from Jiangsu Road station to The Second Bridge Park station, in total of 26 stations. The section between Bus Corporation and Xinzhuang station is dark buried. As shown in figure 2:

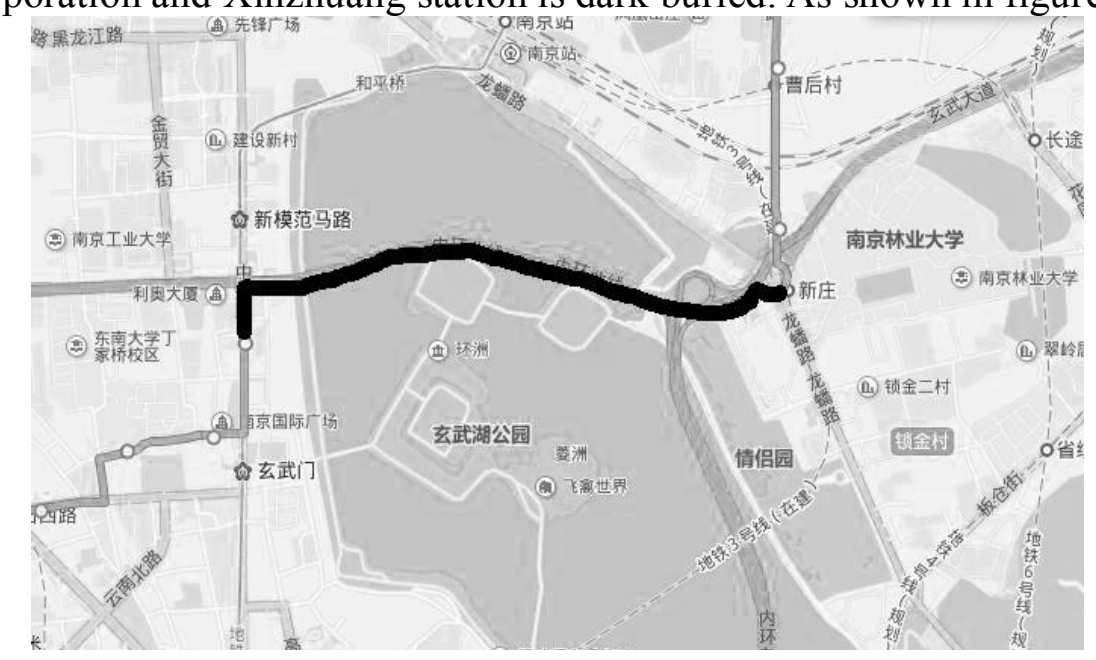

Fig. 2 Bus Corporation - Xinzhuang Station

Xuanwu tunnel passes through the bottom of the lake; "3 g" signal is unstable. After the bus running into the tunnel, dispatching center can not accurately obtain the vehicle position. Control center installs ZigBee wireless trunking communication nodes between the two stations in every 500 meters. Dispatching center can obtain the information of vehicles thought car terminal equipment.

One bus line has 39 vehicles, peak interval is 3 to 4 minutes, flat peak interval is 6 to 7 minutes, and trough interval is 10 minutes at night. When an accident happened in tunnel at peak, dispatching center contacted the driver immediately to know site condition, and chose the most appropriate management. Then passenger evacuate, at the same time, the next bus run to Bus 
Corporation directly without stopping at Dingjia Bridge station. Scheduling information displayed on the electronic platform screen. At the departure point, control center added two buses, the interval reduced to 2 minutes until the line recovered. Flat peaks and valleys operating periods, center does not increase the starting station vehicles.

\section{Conclusion}

Public traffic safety problem is a common problem around the world; this paper summarizes security of public transportation. It seeks method to remit traffic crisis from two aspects of crisis identification and the scheduling. We can get the traffic information outside the car though contact driver timely and combine with GIS technology and the road fixed cameras. After identifying the crisis, this paper confirms the single line and regional dynamic scheduling from the angle of bus scheduling. Regional scheduling need further study.

\section{References}

[1]LI NI.The Study of the Problem of Road Traffic Crisis Emergency Management System in Our Country.Transportation Enterprise Management, 2008, 23(11)72-73.

[2]JIANG HAN-FANG. The Study of Public Transport Safety Management Research. China Management Magazine, 2012, 19:435.

[3]JIANG BO, ZOU WEI. Elaborating Intelligent Traffic Management Planning System Based on GIS[J].Research and Exploration in Laboratory, 2012, 30(4): 62-66.

[4]Wang jia. “3G” Technology Applied in City Intelligent Public Traffic.Da Lian, 2012.

[5]Guo Zhitao. The Study of RFID Technology Applied in Public Scheduling. HeBei. 2011.

[6]Gao Hui. The Study of ZigBee Technology Applied in Intelligent Public Transport Scheduling.Xiean.2007

[7]ANNIE UTHRA R., KASMIR RAJA S. V., JEYASEKAR A.,et al. A Probabilistic Approach for Predictive Congestion Control in Wireless Sensor Networks[J]. Annie Uthraetal. / J Zhejiang Univ-Sci C (Comput \& Electron) 2014, 15(3):187-199.

[8]CHENG M, GONG X, CAI L. Joint Routing and Link Rate Allocation Under Bandwidth and Energy Constraints in Sensor Networks. IEEE Trans. Wirel. Commun, 2009, 8(7): 3770-3779.

[9]DIAO LI,SHEN LIAN-FENG,HU JING.Intelligent Transportation Supervision and Dispatch system[J].Journal of Data Acquisition \& Processing, 2012, 1(27):147-152.

[10]REN F, HE T, DAS S, et al,Traffic-aware Dynamic Routing to Alleviate Congestion in Wireless Sensor Net-works. IEEE Trans. Parall. Distr. Syst, 2011, 22(9):1585-1599.

[11]UTHRA R, RAJA S, QoS Routing in Wireless Sen-sor Networks-a Survey. ACM Comput. Surv, 2012, 45(1): 9.1-9.12

[12] WU Y, YUAN Z, WU Y. A Predictive Control Strategy for Networked Control System with Destabilizing Trans-mission Factors. Adv. Sci. Eng. Med, 2013, 5(1): 83-90.

[13]He Di. The Study of Public Vehicles Regional Scheduling on APTS.Chong Qing.2009.

[14]BHARGAVAV, JOSEJ, SRINIVASAN K,et al. Q-CMRAQueue-based Channel-measurement and Rate-allocation. IEEE Trans. Wirel. Commun. 2012, 11(11): 4214-4223. 